\title{
Controlling microstructure evolution and phase transformation behavior in additive manufacturing of nitinol shape memory alloys by tuning hatch distance
}

\author{
Jia-Ning Zhu' ${ }^{1, *}$ (D), Evgenii Borisov ${ }^{2}$, Xiaohui Liang ${ }^{1}$, Richard Huizenga ${ }^{1}$, Anatoly Popovich², \\ Vitaliy Bliznuk ${ }^{3}$, Roumen Petrov ${ }^{1,3}$, Marcel Hermans ${ }^{1}$, and Vera Popovich ${ }^{1,2, *}$ \\ ${ }^{1}$ Department of Materials Science and Engineering, Delft University of Technology, Delft, The Netherlands \\ ${ }^{2}$ Peter the Great Saint-Petersburg Polytechnic University, Saint Petersburg, Russia \\ ${ }^{3}$ Department of Electrical Energy, Metals, Mechanical Constructions \& Systems, Ghent University, Ghent, Belgium
}

Received: 25 November 2021 Accepted: 8 February 2022 Published online:

3 March 2022

(C) The Author(s) 2022

\begin{abstract}
Laser powder bed fusion (L-PBF), categorized as additive manufacturing technique, has a capability to fabricate NiTi (Nitinol) shape memory alloys with tailorable functional properties and complex geometries. An important processing parameter, hatch distance (h), is often related to macroscale structural defects; however, its role on controlling the microstructure and functional properties is usually underestimated in L-PBF of NiTi. In this work, equiatomic $\mathrm{NiTi}(50.0$ at $\% \mathrm{Ni})$ parts were fabricated with various hatch distances to tailor the microstructure and their shape memory characteristics. Contrary to what is observed in Ni-rich NiTi alloys, in this work, we demonstrate that phase transformation temperatures of L-PBF equiatomic NiTi do not decrease proportionally with hatch distance but rather relate to a critical hatch distance value. This critical value $(120 \mu \mathrm{m})$ is derived from the synergistic effect of thermal stress and in situ reheating. Below this value, epitaxial grain growth and in situ recrystallization are enhanced, while above, irregular grains are formed and dislocations induced by thermal stresses decrease. However, the critical value found herein is characterized by high dislocation density and fine grain size, resulting in a superior thermal cyclic stability. The proposed finite element model is proven to be an effective tool to understand and predict the effect of hatch distance on grain morphology and dislocation density evolutions
\end{abstract}

Handling Editor: Naiqin Zhao.

Address correspondence to E-mail: J.Zhu-2@tudelft.nl; v.popovich@tudelft.nl

E-mail Addresses: evgenii.borisov@icloud.com; X.Liang-2@tudelft.nl; R.M.Huizenga@tudelft.nl; popovicha@mail.ru;

vitaliy.bliznuk@ugent.be; Roumen.Petrov@UGent.be; M.J.M.Hermans@tudelft.nl 
in L-PBF NiTi SMAs. In the present study, we provide a comprehensive understanding for in situ controlling L-PBF NiTi microstructure and functional characteristics, which contributes to designing 4-dimensional shape memory alloys.

\section{Introduction}

Due to the reversible martensitic phase transformation, shape memory effect (SME) and pseudo-elasticity are manifested in NiTi (Nitinol) shape memory alloys (SMAs) [1, 2]. For near equiatomic NiTi (50 at\% $\mathrm{Ni}$ ) alloys, the reversible martensitic phase transformation can be accomplished by the one-step phase transformation, i.e., the phase transformation between the high-temperature stable austenite (cubic B2-type crystal structure) and the low-temperature stable martensite (monoclinic B19'-type crystal structure) $[1,3,4]$. Owing to their remarkable properties, NiTi SMAs are widely used in fields, such as actuators [5], dampers [6], sensors [7] and medical devices $[8,9]$.

In recent years, the laser powder bed fusion (LPBF) technique has attracted a lot of attention in the fabrication of NiTi parts [10-13], because of its ability to build parts with complex structures [14, 15] and in situ tailorable microstructures [16, 17]. For the fabrication of L-PBF NiTi parts, main processing parameters include laser power $(P, \mathrm{~W})$, scanning velocity $\left(v, \mathrm{~mm} \mathrm{~s}^{-1}\right)$, layer thickness $(t, \mu \mathrm{m})$ and hatch distance $(h, \mathrm{~mm})$. In the past, most studies focused on investigating the effect of laser powers and scanning velocities (related to the so-called linear energy density: $E_{l}=\frac{P}{v}, \mathrm{~J} \mathrm{~mm}^{-1}$ ) on structural quality, microstructure evolution and functional properties [18-22]. The layer thickness was usually chosen between 30 and $50 \mu \mathrm{m}$ to achieve the balance among full-dense parts, stable powder spreading and desirable building rate [22-25]. However, the hatch distance was mainly selected as a fixed value to prevent structural defect formation (such as lack of fusion and surface roughness) [26-28], and its role in microstructural evolution, phase transformation behavior and functional properties were underestimated and ignored.

As found in recent studies [29-31], the hatch distance is an unneglectable factor, which can affect not only structural defects but also exert a significant effect on the microstructure and phase transformation temperatures (PTTs) in Ni-rich L-PBF NiTi alloys. However, microstructural evolution mechanisms and changes in phase transformation temperatures of L-PBF NiTi alloys with various hatch distances have not been revealed yet. For Ni-Ti alloys, it has been demonstrated that phase transformation behavior can be affected by the $\mathrm{Ni} / \mathrm{Ti}$ ratio [32], precipitates [32, 33], dislocations [33, 34] and grain size $[35,36]$. PTTs increase dramatically (around $100 \mathrm{~K}$ at $\%^{-1}$ ) with decreasing $\mathrm{Ni}$ content in Ni-rich NiTi alloys [32,37], while for equiatomic or Ti-rich NiTi alloys, PTTs almost do not change with the chemical composition ratio of Ni/Ti [37]. Similarly, precipitates only affect the PPTs significantly in $\mathrm{Ni}$-rich rather than equiatomic or Ti-rich NiTi alloys [32, 38]. Dislocations can decrease PTTs by hindering martensite transformation during cooling [33]. Decreasing grain size can cause a suppression of the thermally induced martensitic phase transformation occurring, also resulting in a decreasing PTTs [35]. Due to a higher vapor pressure and lower boiling point of Ni compared with $\mathrm{Ti}$ in binary NiTi alloys $[29,31], \mathrm{Ni}$ is preferentially evaporated from NiTi alloys and the chemical composition ratio of $\mathrm{Ni} / \mathrm{Ti}$ decreases after L-PBF. Considering the sensitivity of transformation temperature by $\mathrm{Ni} / \mathrm{Ti}$ ratio and $\mathrm{Ni}$ rich precipitates in $\mathrm{Ni}$-rich alloys, an equiatomic $\mathrm{NiTi}$ composition was selected to focus on understanding how to control phase transformation behavior and microstructure evolution by tuning the hatch distance.

In addition, it was found that dislocation density, impeding martensitic transformations, increases with widening the hatch distance [29], but only two hatch distance conditions were conducted/considered, which brings uncertainty about the relationship between the hatch distance and dislocation density.

In this work, L-PBF NiTi alloys with various hatch distances $(100,120$, and $140 \mu \mathrm{m})$ were successfully fabricated. The effect of hatch distance on microstructure, dislocation density, phase transformation behavior and thermal cyclic stability was 
systematically investigated by experiments as well as finite element modeling (FEM). Considering the sensitivity of transformation temperatures by $\mathrm{Ni} / \mathrm{Ti}$ ratio and Ni-rich precipitates in Ni-rich alloys, an equiatomic $\mathrm{NiTi}$ composition (Ni: 50.0 at\%) was selected in this work in order to understand how to control phase transformation behavior and microstructure evolution by tuning hatch distance.

\section{Materials and methods}

\section{Experimental}

\section{Fabrication}

Commercial NiTi $(50.0$ at $\% \mathrm{Ni}$ ) powder manufactured by the gas atomization (TLS Technik $\mathrm{GmbH}$, Bitterfeld, Germany) was used as the initial powder for L-PBF fabrication. The NiTi powders contain spherical particles with the following size distribution: D-values: $\mathrm{D}_{10}=23 \mu \mathrm{m}, \quad \mathrm{D}_{50}=40 \mu \mathrm{m}$, $\mathrm{D}_{90}=67 \mu \mathrm{m}$. An Aconity3D Midi (Aconity3D GmbH, Germany) machine equipped with a laser source featuring a maximum power of $1000 \mathrm{~W}$ and a beam with a Gaussian distribution were used to fabricate L-PBF NiTi parts. According to the CAD model, the Nitinol samples were built up layer by layer. To prevent cracking, a $67^{\circ}$ scanning rotation between the adjacent layers was applied [39]. L-PBF samples were fabricated in a cylindrical shape with a diameter of $6 \mathrm{~mm}$ and a height of $20 \mathrm{~mm}$.

To estimate the energy input during the L-PBF process, the volumetric energy density $E_{v}$ was applied:

$E_{v}=\frac{P}{v \times h \times t}$

where $\mathrm{P}$ denotes laser power $(\mathrm{W}), \mathrm{v}$ scanning speed $\left(\mathrm{mm} \mathrm{s}^{-1}\right), \mathrm{h}$ hatch distance $(\mu \mathrm{m})$, and t layer thickness $(\mu \mathrm{m})$.

In present study, to investigate the effect of $h$, various $\mathrm{h}$ values of 100, 120 and $140 \mu \mathrm{m}$ were used, while the other parameters were kept constant $(\mathrm{P}=250 \mathrm{~W}$, $\mathrm{v}=1250 \mathrm{~mm} \mathrm{~s}^{-1}$, and $\left.\mathrm{t}=30 \mu \mathrm{m}\right)$. The L-PBF processing parameters are summarized in Table 1.

\section{Characterization}

To investigate microstructure, cross sections along the building direction and the top view
Table 1 Processing parameters for the L-PBF-fabricated NiTi samples, A1-A3

\begin{tabular}{lrrr}
\hline Parameters & A1 & A2 & \multicolumn{1}{c}{ A3 } \\
\hline Laser power $(\mathrm{W})$ & 250 & 250 & 250 \\
Scan velocity $\left(\mathrm{mm} \mathrm{s}^{-1}\right)$ & 1250 & 1250 & 1250 \\
Hatch distance $(\mu \mathrm{m})$ & 100 & 120 & 140 \\
Layer thickness $(\mu \mathrm{m})$ & 30 & 30 & 30 \\
Laser beam diameter $(\mu \mathrm{m})$ & 80 & 80 & 80 \\
Volume energy density $\left(\mathrm{J} \mathrm{mm}^{-3}\right)$ & 67 & 56 & 48 \\
\hline
\end{tabular}

(perpendicular to the building direction) were prepared. Samples for metallographic examination were ground, polished and etched in two types of etching solution. The first-type etching solution consisting of $\mathrm{HF}$ (3.2 vol\%), $\mathrm{HNO}_{3}(14.1 \mathrm{vol} \%)$ and $\mathrm{H}_{2} \mathrm{O}$ (82.7 vol\%) was used to distinguish epitaxial grain growth [18]. A second solution consisting of $120 \mathrm{ml}$ distilled water, $15 \mathrm{ml} \mathrm{HCl}, 15 \mathrm{~g} \mathrm{Na}_{2} \mathrm{~S}_{2} \mathrm{O}_{5}, 10 \mathrm{~g} \mathrm{~K}_{2} \mathrm{~S}_{2} \mathrm{O}_{5}$ and $2 \mathrm{~g} \mathrm{NH}_{4}$ HF was used for identifying parent grains [40] (austenitic grains) with the help of linearly polarized light (LEICA DML 5000 light optical microscope). The average grain width was measured by the line intercept method [41], and the columnar architectures within molten pools were treated as different grains [42]. For investigating hardness of L-PBF NiTi alloys, hardness was measured by an automatic microhardness tester (Buehler Vickers) under the test force $19.61 \mathrm{~N}$ (denoted as HV 2). Each sample was indented 20 indentations to obtain the mean hardness and standard deviation.

Differential scanning calorimetry (DSC) was conducted to determine phase transformation temperatures of NiTi alloys (including martensite starting temperature $\left(\mathrm{M}_{\mathrm{s}}\right)$, martensite finishing temperature $\left(\mathrm{M}_{\mathrm{f}}\right)$, austenite starting temperature $\left(\mathrm{A}_{\mathrm{s}}\right)$ and austenite finishing temperature $\left.\left(\mathrm{A}_{\mathrm{f}}\right)\right)$, and thermal cycling stability. For this purpose, a PerkinElmer DSC 800 was used in the temperature range between 203 and $473 \mathrm{~K}$ with a heating and cooling rate of $10 \mathrm{~K} \mathrm{~min}^{-1}$. In total, 10 DSC thermal cycles were carried out for each specimen. To confirm the experimental accuracy, DSC measurements were repeated twice for each processing condition. Each DSC sample of approximate $1 \mathrm{~mm}$ thickness was sliced from the middle of the L-PBF Nitinol samples by using electrical discharging machining (EDM) and then was ground and polished to remove EDM damage. All

\section{Springer}


characteristic temperatures were determined by using the intersecting tangents method [43].

Dislocations and precipitates of fabricated NiTi samples were investigated using a JEM-2200FS transmission electron microscope (TEM) equipped with an energy dispersive spectrometer (EDS) system. The TEM specimens were prepared by electropolishing disks with a diameter of $3 \mathrm{~mm}$ in a twinjet electropolisher using 10\% perchloric acid and $90 \%$ ethanol as electrolytes.

Due to overlapping NiTi martensitic peaks at room temperature, it is difficult to investigate the broadening of XRD peaks. Hence, the high-temperature $X$-ray diffraction (XRD) for achieving parent phase phases was used in this work. All samples were heated to $423 \mathrm{~K}$ (higher than $\mathrm{A}_{\mathrm{f}}$, but not causing recovery/recrystallization [44]) during the XRD measurements. The XRD (Bruker D8 Discover diffractometer, Incoatec Microfocus Source $(\mathrm{I} \mu \mathrm{S})$ ) measurements were conducted between $38^{\circ}$ and $150^{\circ}$ using a diffractometer with a $\mathrm{Cu}$ target, a step size of $0.04^{\circ} 2 \theta$ and the counting time $20 \mathrm{~s}$ per frame. $\mathrm{LaB}_{6}$ powder was used for the determination of the instrumental contributions to the peak width.

\section{Finite element modeling}

To study the effect of hatch distance on melt pool dimensions and their temperature field, finite element analysis (FEA) was employed. A 3D thermal analysis model was developed using COMSOL Multiphysics Modeling Software (Version 5.5, COMSOL Ltd., Cambridge, UK).

\section{Governing equations and volumetric heat source}

The thermal field was obtained by solving the following transient 3D heat conduction equation using the temperature-dependent thermal properties of the material:

$\rho(T) C_{p}(T) \frac{\partial T}{\partial t}+\rho(T) C_{p}(T) v \nabla T=Q+\nabla(k(T) \nabla T)$

where $\rho(T)\left(\mathrm{kg} \mathrm{m}^{-3}\right)$ is the temperature-dependent density, $C_{p}(T)\left(\mathrm{J} \mathrm{kg}^{-1} \mathrm{~K}^{-1}\right)$ is the temperature-dependent specific heat capacity, $k(T)\left(\mathrm{W} \mathrm{m}^{-1} \mathrm{k}^{-1}\right)$ is the temperature-dependent thermal conductivity, $Q$ $\left(\mathrm{W} \mathrm{mm}^{-3}\right)$ is the net volumetric heat flux, and $\mathrm{v}(\mathrm{mm}$ $\mathrm{s}^{-1}$ ) is the laser scanning velocity.
The temperature-dependent thermal-physical properties $[45,46]$ used in this work were taken from the literature or calculated by using Thermo-Calc software (Version 2020a, Thermo-Calc, Stockholm, Sweden) based on TCHEA2 (High Entropy Alloys version 2.1) database (Fig. 1). Considering the thermocapillary flow within melt pools, artificially corrected factor $\alpha$ was induced as $k_{2}=\alpha k_{1}$ (since only the conduction mode melt pool was shown in this work, $\alpha$ is selected as 2.5 [47]) when temperature is higher than the melting point of $\mathrm{NiTi}$, where $k_{1}$ is the usual thermal conductivity of NiTi and $k_{2}$ is the modified one $[47,48]$.

Due to the lack of experimentally measured laser absorptivity, the Rosenthal equation was used to estimate the laser absorptivity of NiTi powder layers based on experimentally measured melt pool width [49]. The calculated laser absorptivity was found as 0.4 [49]. The applied laser energy is separated into three portions, including reflection, absorption and transmission of power. Only the absorbed energy is used to melt the powders and previously solidified layers. The laser energy can travel a certain depth along the powder bed. Therefore, the heat transfer through the depth direction on the powder bed was also considered in the present model. The laser penetration depth can be estimated based on the BeerLambert attenuation law. Therefore, the volumetric heat flux can be expressed as:

$Q(x, y, z)=\frac{Q_{0}(x, y)}{\delta} \exp \left(-\frac{|z|}{\delta}\right)$

where $Q_{0}$ is the heat flux on the upper surface (W $\left.\mathrm{m}^{-2}\right), \delta=65 \mu \mathrm{m}$ is the optical penetration depth $(\mu \mathrm{m})$ of the used material [50], and $|z|$ is the absolute value of the $\mathrm{z}$-coordinate.

The distribution of surface heat flux $Q_{0}$ across the powder bed is presumed to be Gaussian, which can be mathematically represented as:

$Q_{0}(x, y)=\frac{2 A P}{\pi R^{2}} \exp \left(-\frac{2\left((x-v t)^{2}+y^{2}\right)}{R^{2}}\right)$

where $\mathrm{P}$ is the laser power, $\mathrm{A}$ is the laser absorptivity of materials, and $\mathrm{R}$ is the laser beam radius at which the energy density is minimized to $1 / \mathrm{e}^{2}$ of that at the center of the laser spot. In this work, the laser absorptivity A is 0.40 , which is derived from the Rosenthal equation and the experimental result of melt pool width [49]. 
Figure 1 Temperaturedependent thermal-physical properties of nitinol alloys used for FEA: a the density, b the specific heat capacity, and $\mathrm{c}$ the thermal conductivity. (a)
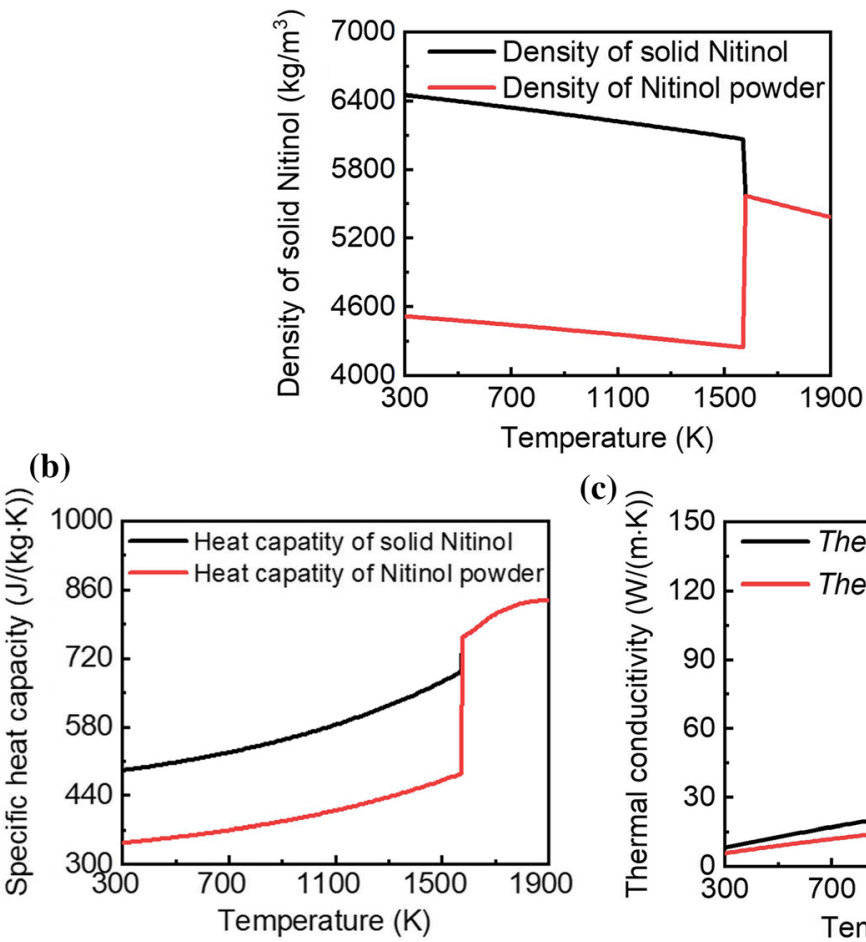

(c)

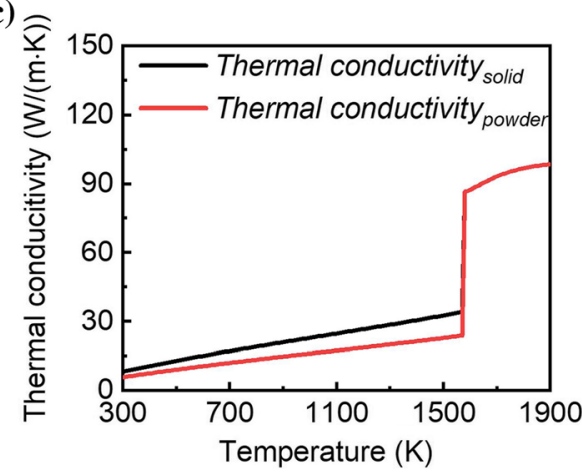

\section{Geometrical description of modeling}

To investigate the effect of hatch distance on melt pool dimensions and thermal gradients, single-track simulations are presented. The schematic of the designed geometry for investigating the effect of various hatch distances is shown in Fig. 2. Considering that hatch distances directly affect overlapping ratios between adjacent laser tracks, previously solidified parts should be included when applying various hatch distance conditions during FEM simulations. Therefore, the top layer was divided into two parts, i.e., the previously solidified part and the powder part. The hatch distance was reflected by the

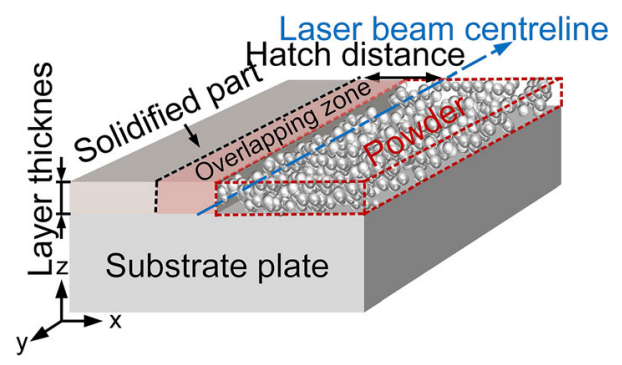

Figure 2 The schematic geometry for simulation of various hatch distances in the single laser track. width of the overlapping zone and can be adjusted by changing the laser beam centerline position (Fig. 2).

To understand thermal histories during L-PBF processes, multiple tracks FEM simulations were carried out in the same layer. The 3D finite element model and the scanning strategy are shown in Fig. 3. In total, 9 tracks were simulated to make L-PBF parts cooling down to the NiTi recrystallization temperature $(873 \mathrm{~K})$ [44].

\section{Results}

\section{Microstructure evolution as a function of hatch distance}

Optical micrographs of samples A1-A3 fabricated with various hatch distances $h$ of 100, 120, and $140 \mu \mathrm{m}$ are shown in Fig. 4 . It can be seen that the grain size and morphology are highly affected by the hatch distances. From the top view of all samples, grain morphologies change from square-like $(100 \mu \mathrm{m})$ to polygon-like and finally show irregular shaped $(140 \mu \mathrm{m})$ (Fig. $4 \mathrm{a}-\mathrm{c})$. From the side view, the grains change from columnar to more equiaxed-like grains with increasing hatch distance (Fig. $4 \mathrm{~d}-\mathrm{f}$ ). It should be noted that the grains in the sample with 
Figure 3 a The 3D finite element model and a the scanning strategy.

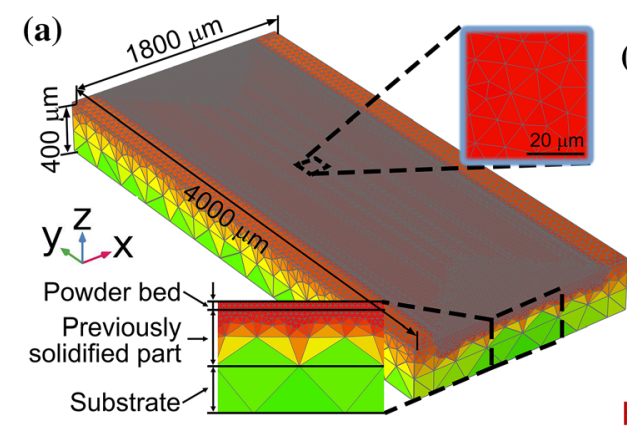

(b)

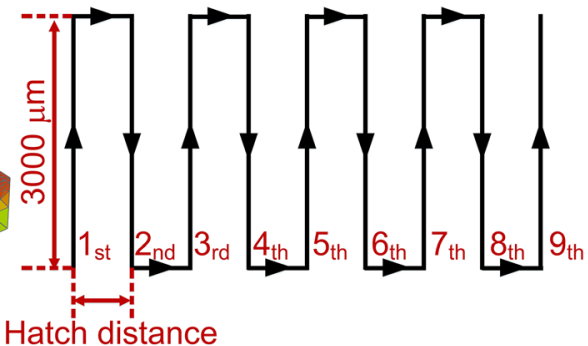

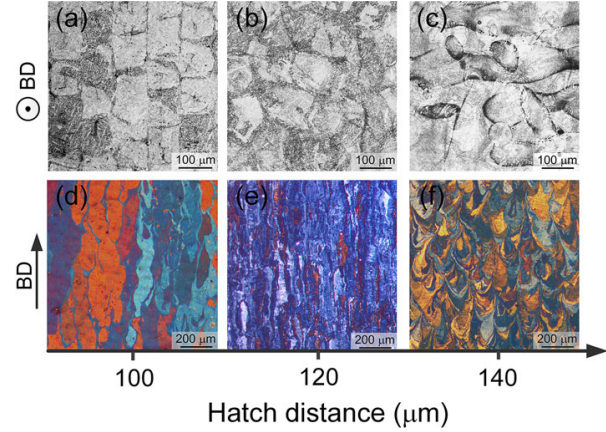

Figure 4 Optical micrographs for the NiTi alloys fabricated with different hatch distances $h$ of $\mathbf{a}, \mathbf{d} 100 \mu \mathrm{m}, \mathbf{b}, \mathbf{e} 120 \mu \mathrm{m}$, and c, f $140 \mu \mathrm{m}$. Pictures $\mathbf{a}-\mathbf{c}$ display the cross section perpendicular to the building direction (BD), and pictures $\mathbf{d}-\mathbf{f}$ were taken under the polarized light condition (to show the grain boundaries of the parent phase) parallel to the BD.

$140 \mu \mathrm{m}$ hatch distance do not show epitaxial growth to subsequent layers, contrary to what is observed in samples with 100 and $120 \mu \mathrm{m}$ hatch distances.

Figure 5 depicts the average grain width, length and aspect ratios (the ratio of grain length to the grain width) for the various hatch distance conditions. Both grain width and length show the monotonically decreasing trend with increasing the hatch distance (Fig. 5a). The average grain width decreases from $\sim 58$ to $29 \mu \mathrm{m}$, and the average grain length decreases from $\sim 454$ to $167 \mu \mathrm{m}$ (Fig. 5a). However, the length-to-width aspect ratio of the grains shows an initial increase and then a decrease (Fig. 5b), implying three types of grain growth characteristics for these three hatch distance conditions. With increasing hatch distance from 100 to $120 \mu \mathrm{m}$, fine width grains were obtained (due to the weakening of reheating induced ripening effect [40] (Fig. 4d, e)). Then, with further increasing hatch distance to $140 \mu \mathrm{m}$ the grain growth changes from columnar grain growth (Fig. 4e) to equiaxed grain growth (Fig. 4f).

SEM observations on the top surfaces are shown in Fig. 6. The melt tracks and corresponding boundaries can be traced in Fig. 6a-c (red dash lines). Parent grain (austenitic grains) boundaries are contoured by yellow dash lines in Fig. 6d, e which indicates grain morphology change from equiaxed to cellular structures with increasing hatch distance from 100 to $140 \mu \mathrm{m}$. As shown in Fig. 6g-e, finer cellular structures were observed at melt track boundaries, and such microstructures are different from those fabricated via conventional methods (such as wrought and powder metallurgy) [51-53]. These features result from heterogeneous nucleation induced by the re-melting of previously solidified tracks at the melt pool boundaries [54].
Figure 5 a The austenitic grain width and length; $\mathbf{b}$ the aspect ratio (the ratio of grain length to the grain width) of grains in all hatch distance conditions.
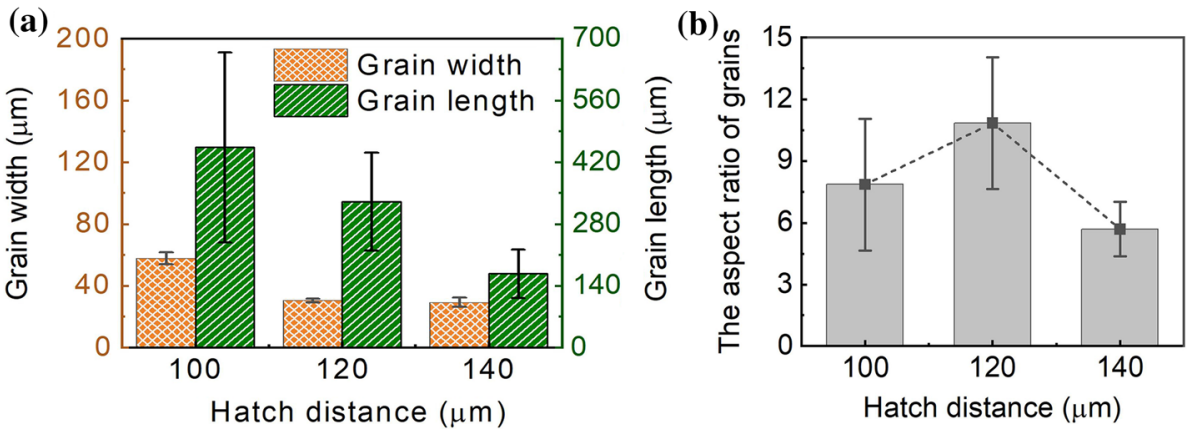


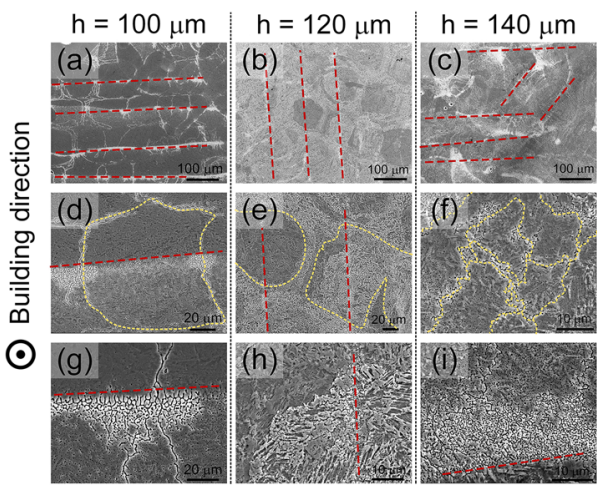

Figure 6 SEM micrographs for the NiTi alloys fabricated with different hatch distances of $\mathbf{a}, \mathbf{d}$, and $\mathbf{g} 100 \mu \mathrm{m}, \mathbf{b}$, e, and h $120 \mu \mathrm{m}$ and $\mathbf{c}, \mathbf{f}$, and $\mathbf{i} 140 \mu \mathrm{m}$. All pictures are depicted on the cross-section perpendicular to the building direction (BD) (Melt tracks were shown as red dash lines, and parent grains were circled by yellow dash lines).

\section{The effect of hatch distance on micro-} hardness, chemical composition and phase transformation behavior

As shown in Fig. 7a, the micro-hardness increases with hatch distance (from $\sim 193$ to $226 \mathrm{HV}$ ). It appears that the chemical composition changes, i.e., the $\mathrm{Ni}$ content increases with the hatch distance (due to reducing the extent of element evaporations) (Fig. $7 \mathrm{~b}$ ). To investigate the effect of hatch distance on the phase transformation behavior of L-PBF NiTi samples, DSC measurements were conducted. Unlike the monotonically increasing correlation between the micro-hardness or Ni content and the hatch distance, the L-PBF NiTi sample produced with a $120 \mu \mathrm{m}$ hatch distance shows the lowest phase transformation temperatures among all samples (Fig. 7c, d and Table 2). For NiTi SMAs, phase transformation temperatures mainly depend on $\mathrm{Ni} / \mathrm{Ti}$ ratio [32] and dislocation densities [55]. Generally, the higher the Ni content, the lower the phase transformation temperature [32]. Dislocations can hinder martensitic transition (a higher undercooling is required to trigger the B2 / B19' transformation [56]), resulting in lower phase transformation temperatures. Since the $\mathrm{Ni}$ content increases linearly with the hatch distance (Fig. $7 \mathrm{~b}$ ), phase transformation temperatures should also have a linear relationship with the hatch distance, that is, if only $\mathrm{Ni}$ content plays the dominant role in phase transformation. However, by comparing $\mathrm{Ni}$ content and phase transformation temperatures, it is clear that an additional factor, such as dislocations, may also be involved. Therefore, to investigate the effect of hatch distance on dislocation densities in L-PBF NiTi samples, TEM, high-temperature $\mathrm{XRD}$ and FEM simulations were conducted and presented in the following sections.
Figure 7 a Micro-hardness and $\mathbf{b}$ Ni content of L-PBF samples as a function of hatch distance; c DSC curves for samples with various hatch distances and $\mathbf{d}$ corresponding phase transformation temperatures.
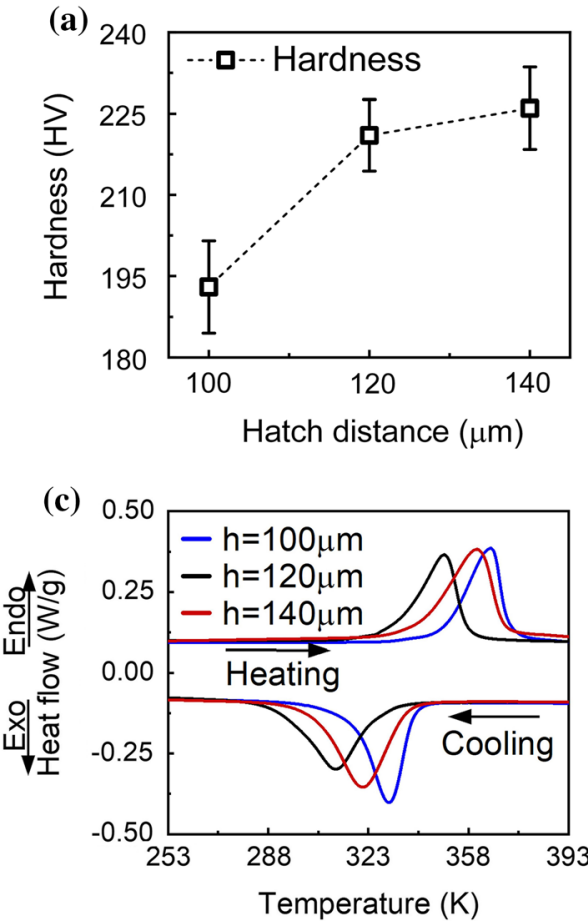
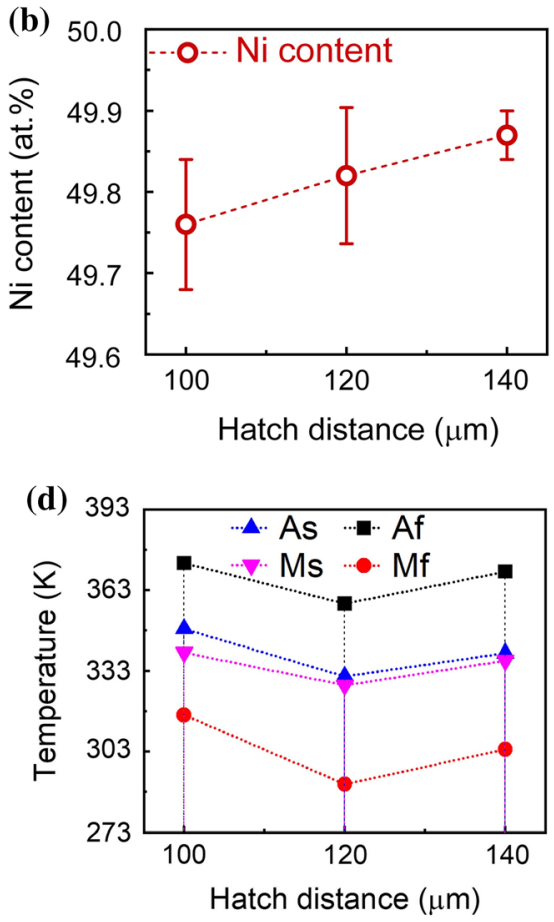
Table 2 Phase transformation temperatures determined by DSC

\begin{tabular}{lrrr}
$\begin{array}{l}\text { Hatch distance }(\mu \mathrm{m}) \\
\text { Characteristic temperature, } \mathrm{K}\end{array}$ & \multicolumn{1}{l}{100} & 120 \\
\hline Martensite starting temperature $\left(\mathrm{M}_{\mathrm{s}}\right)$ & $339.8 \pm 0.6$ & $327.7 \pm 0.9$ & $336.8 \pm 0.6$ \\
Martensite finishing temperature $\left(\mathrm{M}_{\mathrm{f}}\right)$ & $314.4 \pm 0.9$ & $290.9 \pm 0.6$ & $303.8 \pm 1.1$ \\
Austenite starting temperature $\left(\mathrm{A}_{\mathrm{s}}\right)$ & $348.5 \pm 0.3$ & $331.0 \pm 0.2$ & $341.2 \pm 0.2$ \\
Austenite finishing temperature $\left(\mathrm{A}_{\mathrm{f}}\right)$ & $373 \pm 0.3$ & $357.9 \pm 0.2$ & $369.8 \pm 1.2$ \\
\hline
\end{tabular}

\section{TEM observation and high-temperature XRD}

Figure 8 illustrates the representative TEM microstructure of the L-PBF NiTi alloys fabricated with various hatch distances. For all samples, nanosized precipitates in the range of 20-60 nm (marked by orange arrows) were observed. Based on the EDS results, precipitates are $\mathrm{Ti}_{4} \mathrm{Ni}_{2} \mathrm{O}_{\mathrm{x}}$, which are commonly detected in near equiatomic NiTi alloys [57]. It should, however, be noted that the lattice parameters and crystal structure of $\mathrm{Ti}_{2} \mathrm{Ni}$ phase and $\mathrm{Ti}_{4} \mathrm{Ni}_{2} \mathrm{O}_{\mathrm{X}}$ are the same, because $\mathrm{O}$ resides interstitially in the $\mathrm{Ti}_{4}$ $\mathrm{Ni}_{2} \mathrm{O}_{x}$ phase $[58,59]$.

For the sample with $100 \mu \mathrm{m}$ hatch distance, serrated martensite phases with multiple bending were found (Fig. 8a, b). This feature originates from the

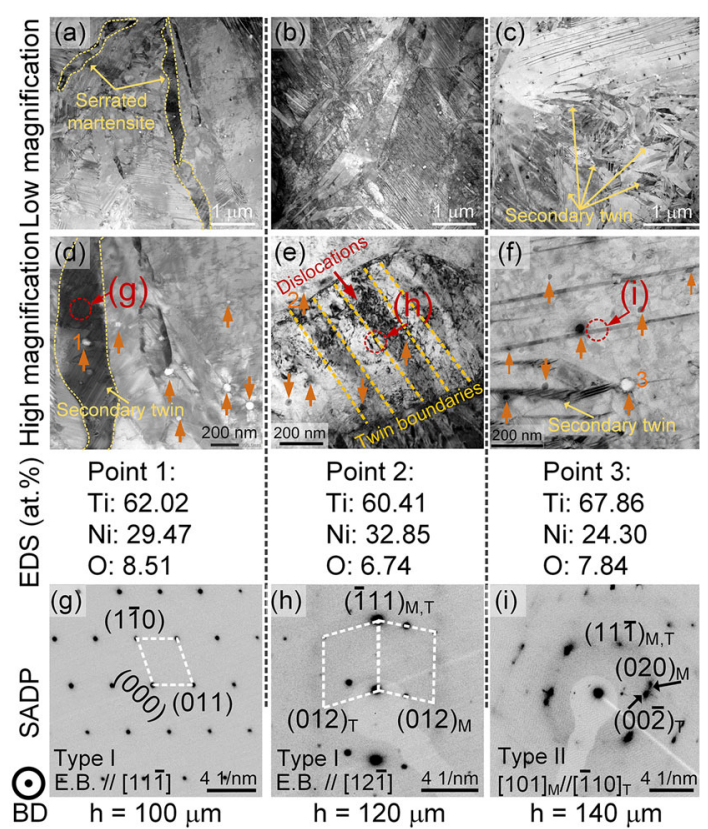

Figure 8 TEM images and corresponding SADPs of L-PBF NiTi fabricated with various hatch distances $h$ of $\mathbf{a}, \mathbf{d}, \mathbf{g} 100 \mu \mathrm{m}, \mathbf{b}, \mathbf{e}$, h $120 \mu \mathrm{m}$, and c, f, i $140 \mu \mathrm{m}$ (the upper part depicts low magnification and the lower part high magnification to distinguish the difference in dislocations and precipitates). shear force subjected to martensite with micro-stresses [60]. Besides, the secondary twin structure was observed in the serrated martensite, which is indexed as the $\{11 \overline{1}\}$ type I twin. Since the secondary twin is related to the local stress concentration [61], it further proved the existence of micro-stress in the sample with $100 \mu \mathrm{m}$ hatch distance. The micro-stress field should be attributed to thermal stress induced by the high cooling rate during L-PBF process.

For the sample with the $140 \mu \mathrm{m}$ hatch distance, martensite phases mainly consist of pure martensite structure of twins and secondary martensite twins (Fig. 8c). The TEM image of pure martensite twins and its corresponding selected area diffraction patterns (SADPs) are shown in Fig. $8 \mathrm{f}$ and i. Some precipitates $\left(\mathrm{Ti}_{4} \mathrm{Ni}_{2} \mathrm{O}_{\mathrm{x}}\right)$ are embedded into martensitic twin boundaries (Fig. 8f). $<011>$ type II twins were determined by its SADPs, which is commonly found in the B19' martensite [61]. The secondary martensite twins indicate the presence of the local stress concentration, which is similar to the sample with $100 \mu \mathrm{m}$ hatch distance.

It should be noted that there are local micro-stresses (implied by secondary martensite twins) in samples with the hatch distance of 100 and $140 \mu \mathrm{m}$, but dislocations were barely observed. These phenomena indicate there is no micro-plastic deformation in the samples with the hatch distance of 100 and $140 \mu \mathrm{m}$. There are two possible reasons for the absence of micro-plastic deformation in L-PBF samples: (1) The local micro-stress is not high enough to activate slip systems [62]; (2) reheating from follow-up laser tracks causes the elimination of dislocations [29]. The corresponding mechanisms are discussed in section "The effect of hatch distance on microstructure".

In contrast, dislocations were observed throughout the martensite matrix of the $120 \mu \mathrm{m}$ hatch distance sample (Fig. 8e), showing a higher dislocation density in the $120 \mu \mathrm{m}$ hatch distance samples. Based on SADPs in the sample with $120 \mu \mathrm{m},\{11 \overline{1}\}$ type I martensite twins were determined. Since this type of 
martensite twins is often observed in deformed NiTi alloys [63], it can further prove that dislocations are induced by micro-plastic deformation in the sample with $120 \mu \mathrm{m}$. Considering that dislocations can hinder martensite transformation and lower phase transformation temperatures, the reason for the lowest phase transformation temperature in the $120 \mu \mathrm{m}$ hatch distance sample (Fig. 7d) is attributed to its high dislocations density.

Although TEM observations can clearly show detailed microstructural characteristics, only locally representative areas were observed and it is hard to quantitatively evaluate dislocation density on a larger scale. Therefore, to quantitatively investigate the dislocation density of these samples, high-temperature XRD measurements were conducted.

In general, the micro-strain induced by dislocations and the crystallite size can cause the broadening of $X$ ray diffraction peak profiles. By calculating the full width at half maximum (FWHM) of the diffraction profiles, the peak broadening can be quantitatively evaluated [62, 64, 65]. Since the main phase is martensite (monoclinic phase, B19') at room temperature for all samples (Fig. 9a), many peaks are overlapping. This complicated the calculation of the FWHM. To overcome this issue, all samples were in situ heated to $423 \mathrm{~K} \quad\left(>\mathrm{A}_{\mathrm{f}}\right)$ to induce austenitization (Fig. 9b). Due to the simple peak profiles and the high symmetry of the high-temperature parent phase (BCC, B2), the evaluation of HT Xray diffraction profile broadening can then be smoothly performed. To improve accuracy of measured FWHM, the instrumental broadening $\left(\beta_{\mathrm{hkl}(\text { Instrumental })}^{2}\right)$ was considered to achieve actual FWHM $\left(\beta_{\mathrm{hkl}}\right)$. The $\beta_{\mathrm{hkl}}$ can be acquired by using the following equation:

$\beta_{\mathrm{hkl}}=\sqrt{\beta_{\mathrm{hkl}(\text { Measured })}^{2}-\beta_{\mathrm{hkl}(\text { Instrumental })}^{2}}$

It can be seen that there are no other peaks around austenite peaks (Fig. 9b), which indicates that all samples are austenitized by heating to $423 \mathrm{~K}$.

To distinguish peak broadening contributions originating from either crystallite size or micro-strain induced by dislocation, Williamson-Hall analysis based on uniform deformation model (UDM) is used $[66,67]$. In the UDM, the Williamson-Hall equation can be written as.

$\beta_{\mathrm{hkl}} \cos \theta=\frac{k \lambda}{D}+4 \varepsilon \sin \theta$

where $v$ is the FWHM, $v$ is the diffraction angle and $\mathrm{k}$ is the shape factor (0.94) [66], $\lambda$ is the wavelength of X-rays used (herein $\mathrm{Cu}-\mathrm{K} \alpha 1$
Figure 9 The $(110)_{\mathrm{B} 2}$ XRD peaks of L-PBF NiTi alloys were measured at $\mathbf{a}$ the room temperature (RT) and $\mathbf{b}$ at $423 \mathrm{~K}\left(>\mathrm{A}_{\mathrm{f}}\right)$; $\mathrm{c}$ the $(110)_{\mathrm{B} 2}$ peaks measured at $423 \mathrm{~K}$ and d linear fitting demonstrating the values of micro-strain $\varepsilon$ varied with hatch distances.
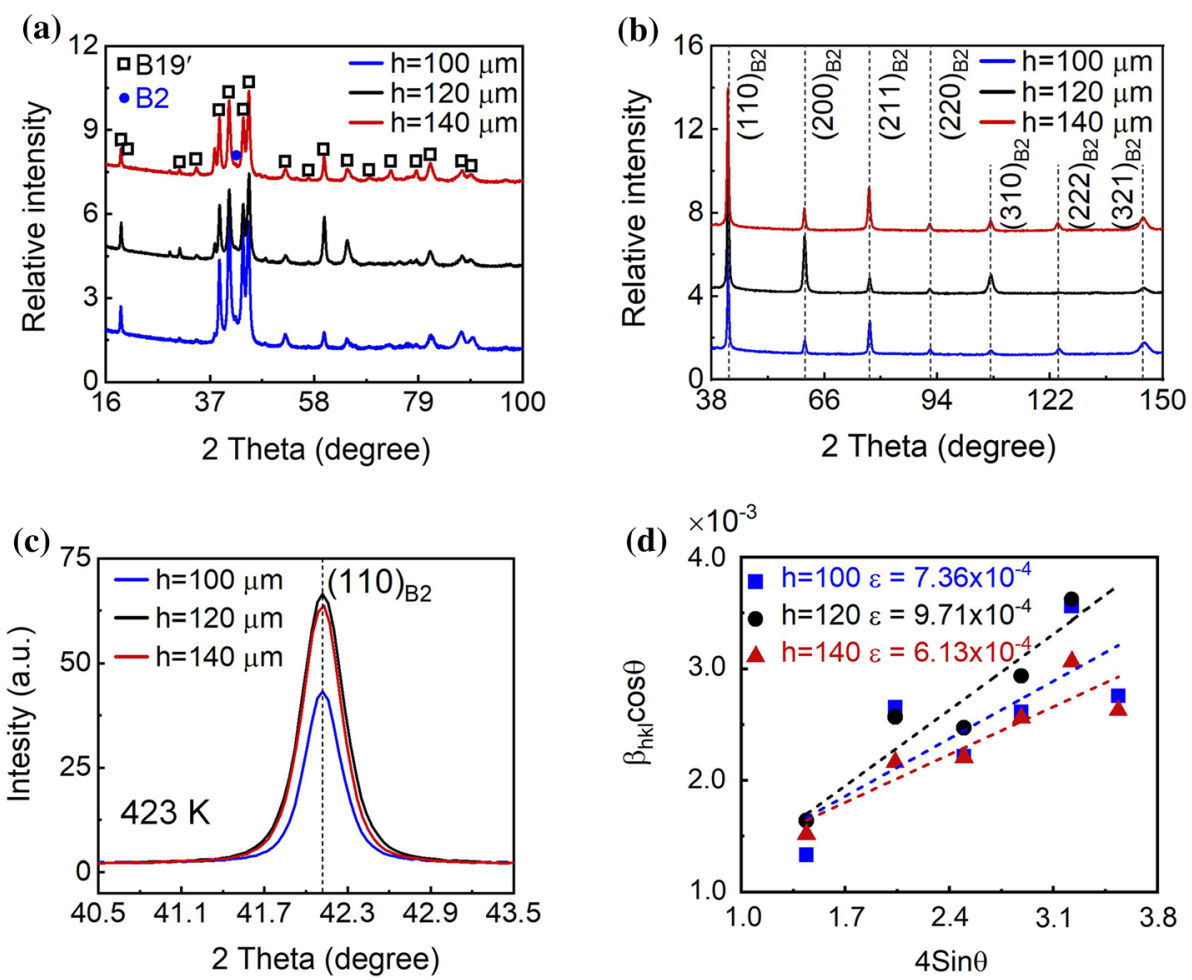
wavelength $=1.540562 \AA$ ), $\mathrm{D}$ is crystallite size, and $\varepsilon$ stands for micro-strain. By plotting $\beta_{\mathrm{hkl}} \cos \theta$ versus the $4 \varepsilon \sin \theta$, the crystallite size can be estimated from the Y-intercept (the intercept is inversely proportional to the crystallite size [68]) and micro-strain induced by dislocation is derived from the fitted slope [68-70] (results shown in Fig. 9d). Then, the dislocation density can be calculated from the obtained micro-strain based on Eq. (6) [62]:

$\rho=14.4 \frac{\varepsilon^{2}}{\|b\|^{2}}$

$\rho$ is dislocation density and $\|\mathrm{b}\|$ is the magnitude of Burgers vector. For BCC structure, the magnitude of Burgers vector is $\|b\|=a / 2 \sqrt{h^{2}+k^{2}+l^{2}}$, where $a$ is the unit cell edge length of the crystal, and $h, k$ and 1 are the components of the Burgers vector [71]. For $\mathrm{NiTi}$, the slip direction is $<111>$ [72] and $\mathrm{a}=3.015 \AA$ [73]. The magnitude of Burgers vector of B2 NiTi can be calculated: $2.61 \times 10^{-10} \mathrm{~m}$. The crystallite size, micro-strain induced by dislocation and dislocation density of austenitic NiTi can be summarized in Table 3. The magnitude of dislocation densities calculated in this work is comparable to other reported works [62, 74]. The sample with $120 \mu \mathrm{m}$ hatch distance has the highest dislocation density, which is consistent with DSC and TEM results.

It should also be noted that L-PBF NiTi consists of both relatively large grains and small size crystallites (measured by XRD) [75]. If the fraction of small size crystallite is comparable with large size grains, peaksplitting will be observed in the XRD patterns [76]. A sharp single peak can be seen in Fig. 9c, indicating negligible amount of small size crystallites. In this case, the change of phase transformation temperature of NiTi with various hatch distances mainly results from different dislocation densities, rather than small size crystallites.

\section{The effect of hatch distance on the cyclic stability of L-PBF NiTi}

For NiTi-based shape memory alloys, cyclic stability is essential to ensure their reliability during engineering applications [3]. To achieve this goal, expensive heat treatments, cold working or severe plastic deformation techniques are generally used [77-80]. However, the above-mentioned methods might not be suitable for L-PBF parts since the predesigned geometry could be changed [81]. Therefore, in situ process tailoring of the microstructure is a good alternative to improve NiTi cyclic stability. This study showed that such processing parameter as hatch distance can significantly tailor the microstructure. Hence, it is important to investigate and understand the effect of hatch distance on the cyclic stability of L-PBF NiTi.

Figure 10 depicts the cyclic DSC response of L-PBF $\mathrm{NiTi}$ alloys fabricated with various hatch distances during multiple thermal cycling. For all samples, the characteristic phase transformation temperatures decrease with increasing number of cycles. (DSC curves gradually shift toward the lower temperature side in Fig. 10a-c.) These phenomena are the socalled thermal cyclic degeneration, which is caused by the accumulation of dislocations and their effect on subsequent transformation cycles [3, 82]. By comparing changes of characteristic phase transformation temperatures after thermal cycling (Fig. 10d), the sample with $120 \mu \mathrm{m}$ hatch distance has the best thermal cyclic stability, and there is almost no change in the austenite finish temperature $\left(\Delta \mathrm{T}_{\mathrm{Af}}=0{ }^{\circ} \mathrm{C}\right)$ and the martensite starting temperature $\left(\Delta \mathrm{T}_{\mathrm{Ms}}=0{ }^{\circ} \mathrm{C}\right)$. In contrast, samples with $100 \mu \mathrm{m}$ hatch distance show 8.2 and $7.6^{\circ} \mathrm{C}$ temperature degenerations for its $A_{f}$ and $\mathrm{M}_{\mathrm{s}}$, respectively. For $140 \mu \mathrm{m}$ hatch distance condition, the sample exhibits 6.8 and $4.6{ }^{\circ} \mathrm{C}$ temperature degenerations. Therefore, the good thermal cycling degeneration resistance is shown in the samples with $120 \mu \mathrm{m}$ hatch distance, indicating a stable working temperature window during thermal cycling.
Table 3 Calculated crystallite sizes, micro-strain, and dislocation densities

\begin{tabular}{llll}
\hline Hatch distance $(\mu \mathrm{m})$ & Crystallite size $(\mathrm{nm})$ & Micro-strain $(\%)$ & Dislocation density $\left(\mathrm{m}^{-2}\right)$ \\
\hline 100 & 190 & $7.36 \times 10^{-2}$ & $1.2 \times 10^{14}$ \\
120 & 478 & $9.71 \times 10^{-2}$ & $2.0 \times 10^{14}$ \\
140 & 238 & $6.13 \times 10^{-2}$ & $7.9 \times 10^{13}$ \\
\hline
\end{tabular}


Figure 10 Effect of hatch distance on the cyclic stability of L-PBF NiTi, determined for 10 thermal cycles determined by DSC: $\mathbf{a} \mathrm{h}=100 \mu \mathrm{m}$, b h $=120 \mu \mathrm{m} \mathrm{c} \mathrm{h}=140 \mu \mathrm{m}$; d characteristic phase transformation temperatures change between the first and $10^{\text {th }}$ thermal cycles as a function of hatch distance.
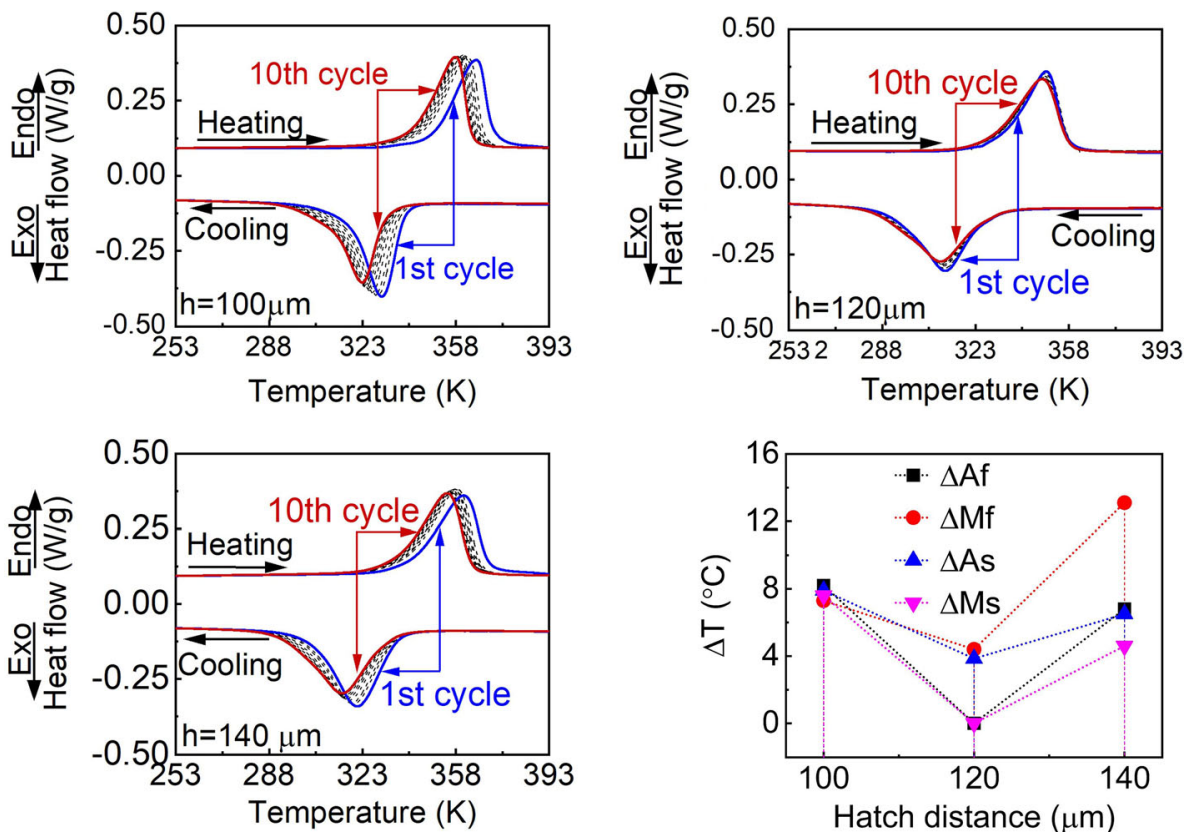

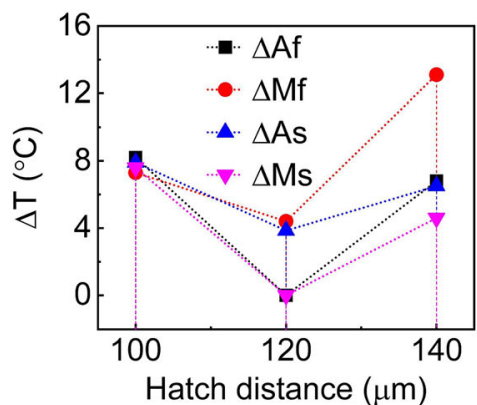

For NiTi, high-density dislocations and ultra-fine grains $(<100 \mathrm{~nm})$ can effectively improve functional stability by impeding dislocation movement during thermal cycling [83, 84]. Since small size crystallites have a very low fraction and their sizes are larger than $100 \mathrm{~nm}$, thermal cyclic stability in all investigated herein L-PBF NiTi depends on only dislocation densities. The sample with $\mathrm{h}=120 \mu \mathrm{m}$ shows the best thermal cyclic stability due to the highest dislocation density $\left(2.0 \times 10^{14} \mathrm{~m}^{-2}\right)$. In contrast, the largest $\Delta \mathrm{T}_{\mathrm{Mf}}$ of $13.1^{\circ} \mathrm{C}$ was seen in the sample with $140 \mu \mathrm{m}$ hatch distance, which has the lowest dislocation density of $7.9 \times 10^{13} \mathrm{~m}^{-2}$ (Table 3).

\section{Discussion}

\section{The effect of hatch distance on microstructure}

In the condition of constant laser power and scanning velocity, hatch distance can determine the overlapping between the adjacent laser tracks. A narrower hatch distance results in a higher overlapping ratio. In this case, more of the previously solidified part is involved in melting of the next laser track. Therefore, the effect of hatch distances on each laser track can be evaluated by tuning the ratio of previously solidified parts in FEM simulations. (The schematic is shown in Fig. 2.) To obtain reliable simulation results and evaluate the predictability of the FEM, 2 more hatch distance values of 80 and $140 \mu \mathrm{m}$ (beyond experimental observations of this work) were also included in FEM simulations.

As shown in Fig. 11a-c, simulated melt pool dimensions are very close to that of the experimentally measured values ( 3\% deviation from experimentally measured melt pool width and depth in the $\mathrm{h}=120 \mu \mathrm{m}$ condition), which indicates the reasonable accuracy of FEM simulations. Based on the results from the single laser track FEM simulations, overlapping zones slightly decrease with increasing hatch distances (Fig. 11a and d) and there will be no overlap (melt pool width smaller than hatch distance) when the hatch distance is larger than $140 \mu \mathrm{m}$ (Fig. 11a), which is consistent with our previous work [12]. In addition, the half widths and depths of melt pool (the part including overlapping zone) increase with hatch distance (Fig. 11c). The reason is attributed to a higher heat capacity, a higher density and a higher thermal conductivity in solid NiTi (lower hatch distance corresponding to more previously solidified parts) compared to NiTi powder, which is inversely proportional to the melt pool dimensions [49].

As reported by Bormann et al. [40], square-like grains from the top view of L-PBF NiTi parts (Figs. 4a, 6d) suggest epitaxial grain growth along the direction perpendicular to the laser beam movement. In this work, the square-like grains gradually 
Figure 11 a The widest cross section of the simulated melt pools featuring various hatch distance conditions:

temperature gradients (the left side) and temperature fields (the right side) (melt pool boundaries are shown as black dash lines); $\mathbf{b}$ the crosssectional L-PBF NiTi fabricated by using $\mathrm{E}_{1}=250 /$ $1250 \mathrm{~J} \mathrm{~mm}^{-1}$ showing melt pool characteristics [12]; c half-width and depth of the melt pools as a function of hatch distance (derived from FEM simulations).

Experimentally measured melt pool half-width and depth are shown as black and red dash lines, respectively;

d temperature gradients in the solid-liquid interface $(\mathrm{Z}=399 \mu \mathrm{m})$ toward $\mathrm{X}$-axis as functions of hatch distance. (a)
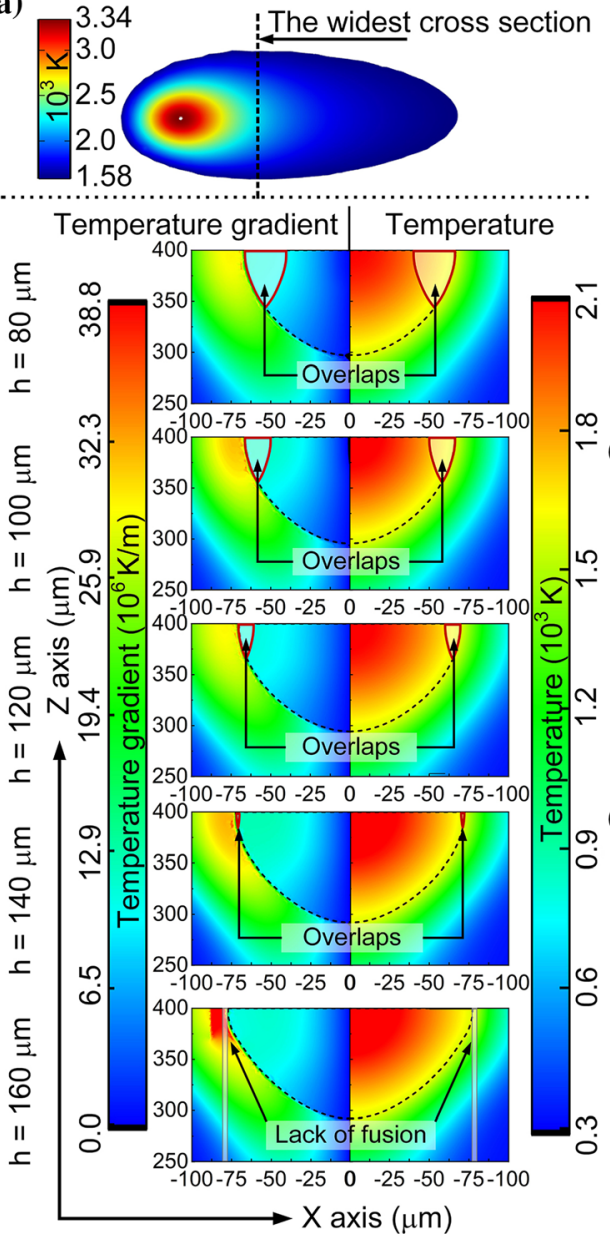
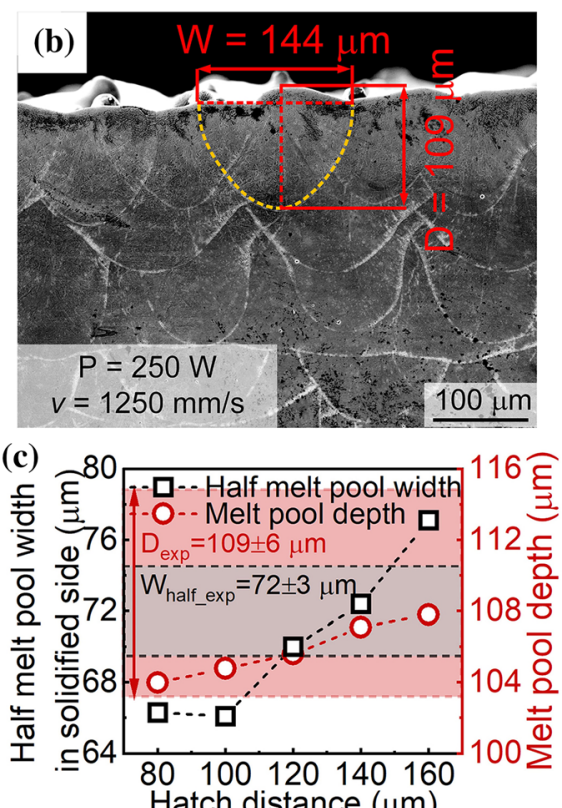

(d)

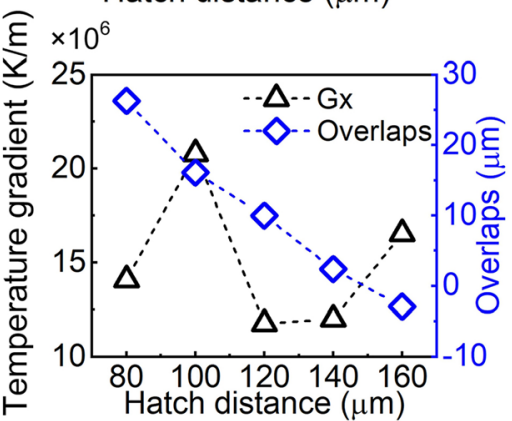

disappear with increasing the hatch distance (Figs. 4a-c, 6d-f), indicating the fading of epitaxial grain growth. To understand the degeneration of epitaxial grain growth, the thermal gradient perpendicular to the laser beam movement direction (i.e., toward X-axis, Gx) in various hatch distance conditions was calculated (Fig. 11d). Generally, grain growth during solidification tends to be along the direction of the largest temperature gradient $[85,86]$, which determines the epitaxial solidification during the L-PBF process [87]. Among all hatch distance conditions, the sample with the hatch distance of $100 \mu \mathrm{m}$ has the highest temperature gradient of $2.1 \times 10^{7} \mathrm{~K} \mathrm{~m}^{-1}$ in front of the solid-liquid interface (Fig. 11d). Therefore, for the sample with $100 \mu \mathrm{m}$ hatch distance it is easier to achieve the epitaxial grain growth than for the samples with other hatch distances. The simulated results also match well with our experimental observations (Figs. 4a-c, 6d-f).
It should be noted that temperature gradient toward X-axis (Gx) increases again when the hatch distance is larger than $120 \mu \mathrm{m}$. However, since the overlap is small (even lack of fusion in the condition of $160 \mu \mathrm{m}$ hatch distance) (Fig. 11a), there is no sufficient nucleation site for the epitaxial grain growth. Hence, the squared-like grains still degenerate into equiaxed grains even the $G x$ increases again (when $\mathrm{h}>120 \mu \mathrm{m})$.

\section{Evolution of dislocations}

The current work demonstrates that the hatch distance shows a significant influence on the dislocation density. The variation of phase transformation behavior with hatch distance is believed to be the direct result of dislocations densities. With the aid of multiple laser track FEM simulations, the dislocation evolution can be connected with the thermal histories of L-PBF NiTi alloys [29]. 
The middle point between the first and second laser tacks is selected as the monitoring point (the schematic is shown in Fig. 12a), which can directly reflect the effect from the following laser tracks. The thermal history profiles of L-PBF $\mathrm{NiTi}$ in various hatch distance conditions (Fig. 12b) can be divided into 3 processes: (1) the first melting process (corresponding to the first peak); (2) the re-melting process (corresponding to the second peak whose temperature is higher than the melting point of NiTi); and (3) the reheating process from the following laser tracks. For the first melting process (Fig. 12c), the peak temperature in the monitoring point decreases with increasing hatch distance and is even lower than the melting point of NiTi when applying $160 \mu \mathrm{m}$ hatch distance. In the reheating stage (Fig. 12d), the higher hatch distance value leads to the lower reheating temperature and the shorter cooling time to trigger in situ annealing, which suggests less heat input for recrystallization of NiTi. By comparing the normalized reheating heat input (with respect to the reheating time) (Fig. 12e), above the recrystallization temperature $873 \mathrm{~K}$ [44]), a narrower hatch distance results in a higher extent of reheating. This accounts for the lower dislocation density (due to recrystallization) (shown in Fig. 8a, d) and the large grain size (due to the Ostwald ripening of grains) (Fig. 4a, d).
Similar phenomena were also observed by Ma et al. [29]. With increasing hatch distance, the extent of reheating is weakened. Hence, more dislocations due to micro-plastic deformation induced by thermal stress will remain in the large hatch distance condition.

In this work, the dislocation density does not decrease linear with increasing hatch distance and is rather determined by the co-effect of the recrystallization triggered by in situ reheating and the microplastic deformation induced by thermal stress (due to thermal shrinkage). For the L-PBF parts, when applying a higher hatch distance, there will be a smaller volumes experiencing thermal shrinkage and this is believed to decrease thermal stress. In this case, a low hatch distance value indicates a high energy input for recrystallization but a high thermal stress level, and vice versa.

In this context, the narrower hatch distance can induce more thermal stresses but also contributes to promoting in situ recrystallization annealing. In contrast, the larger hatch distance can reduce thermal stresses, which is achieved by less volume thermal shrinkages and less heat input for recrystallization. Therefore, dislocations in L-PBF NiTi parts are a result of the competition between micro-plastic deformation induced by thermal stresses and in situ
Figure 12 a The schematic of multiple laser tracks in FEM simulations and the corresponding monitoring point of thermal histories (the middle point between the first and second laser tracks, marked as the red point); b thermal histories of nine tracks for various hatch distances and corresponding enlarged zones for $\mathbf{c}$ the first track and $\mathbf{d}$ reheating from the following tracks; e the average reheating temperatures in various hatch distance conditions.

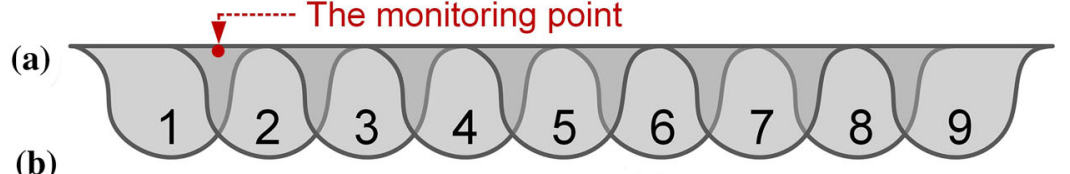

(b)
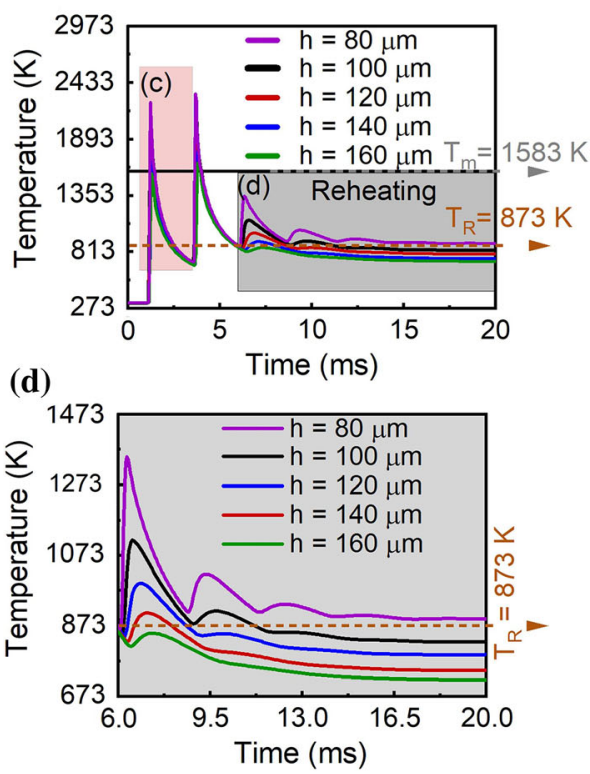

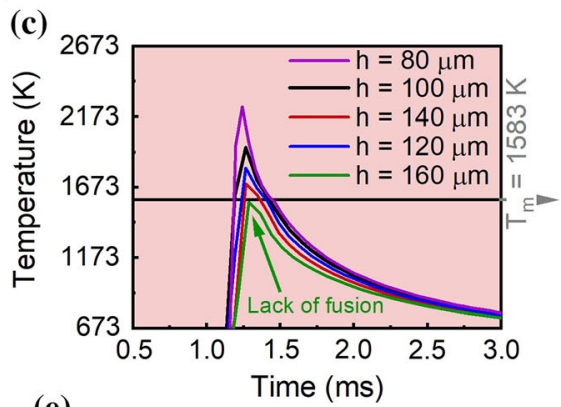

(c)

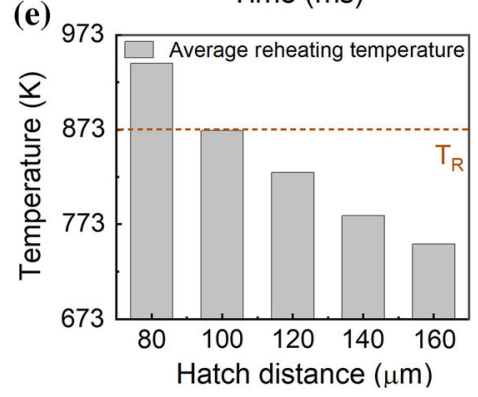


recrystallization. In this study, when the hatch distance is lower than $120 \mu \mathrm{m}$, the in situ recrystallization plays a detrimental role regarding dislocations. While applying the hatch distance larger than $120 \mu \mathrm{m}$, the in situ recrystallization is weakened, whereas the thermal shrinkage volume (related to dislocations) is also reduced. Finally, the $120 \mu \mathrm{m}$ hatch distance is the critical value, which promotes the highest dislocation density in all studied cases.

Based on above results and discussion, it has been demonstrated that hatch distance is a significant and effective processing parameter, which can affect nano- and microstructures of $\mathrm{NiTi}$ shape memory alloys. These structures in turn can determine phase transformation windows and thermal cyclic stability. For L-PBF process, the stable melt pool is determined by laser power and scanning velocity $[12,88]$, and layer thickness is often fixed in the regime of 30-50 $\mu \mathrm{m}$ to ensure stable powder spreading [23]. Hence, hatch distance becomes a desirable processing parameter to be tuned during L-PBF process.

More work regarding cyclic thermal-mechanical testing to investigate the shape memory effect of L-PBF NiTi with various processing parameters will be the scope of our follow-up work.

\section{Conclusions}

The present work investigated the effect of hatch distance on microstructure, phase transformation and thermal cyclic stability in NiTi alloys fabricated via laser powder bed fusion. The effect of hatch distance variation was studied, and it was shown that this parameter significantly affects the microstructure and dislocation evolution allowing for in situ tailoring functional properties. The main findings can be summarized as follows:

(1) NiTi austenitic grain size increases with increasing the hatch distance, and the grain's morphologies change from columnar to equiaxed. The squared-like grains from the top view of the $100 \mu \mathrm{m}$ samples result from the enhanced epitaxial grain growth, which is attributed to a large thermal gradient along the transverse direction (relative to laser beam movement direction).

(2) Phase transformation temperatures change linearly with hatch distance. The lowest phase transformation temperatures are observed in the $120 \mu \mathrm{m}$ hatch distance samples and result from high dislocations density.

(3) Combining TEM, HT-XRD and FEM simulations, mechanisms of grain morphology and dislocation evolutions by applying various hatch distances are revealed. It has been shown that developed herein FEM models are appropriate tools to understand and predict microstructure evolution, which contributes to designing high-performance L-PBF NiTi shape memory alloys.

(4) Due to the pre-existed high dislocations density, the samples with $120 \mu \mathrm{m}$ hatch distance have a better ability to resist micro-plastic deformation induced by the phase transformation. As a result, the best thermal cyclic stability is found in all studied $120 \mu \mathrm{m}$ samples.

(5) Hatch distance can affect the amount of heated volumes and reheating levels, which is related to thermal stresses and in situ recrystallization. The thermal stress can trigger dislocations by micro-plastic deformation, and in situ recrystallization can decrease dislocation densities. Through the competition between the two mentioned factors, different dislocation densities are shown in samples with various hatch distances.

In summary, the current results illustrate that the hatch distance should be of concern not only regarding the structural defects but also as a significant factor that contributes to tailoring microstructure, dislocation densities, phase transformation windows and thermal cyclic stability in NiTi alloys. This work shows a new insight for fabricating in situ tailorable L-PBF NiTi alloys and demonstrates a predictive model to evaluate further the various hatch distance effects. In the field of $4 \mathrm{D}$ printing metallic materials, phase transformation windows and microstructure (related to thermal-mechanical responses) are two concerning factors. Therefore, findings of this work provide a fundamental understanding about tailoring the two factors by tuning hatch distance, which can provide a novel pathway to design in situ tailorable $4 \mathrm{D} \mathrm{NiTi}$ shape memory alloys. In the future, more work related to the influence of hatch distance on the thermal-mechanical SME properties and functional fatigue in L-PBF NiTi will be conducted. In this case, an integrated design 
framework from processing parameters to microstructural and then to functional properties will be established.

\section{Acknowledgements}

Jia-Ning Zhu wishes to thank the China Scholarship Council (CSC) for financial support. The authors also would like to acknowledge the help about the DSC measurements and analysis from Dr. J.C. Bijleveld at the faculty of Aerospace Engineering of Delft University of Technology.

\section{Author contribution}

JNZ contributed to conceptualization, methodology, formal analysis, experimental validation and writing-original draft. EB was involved in methodology and writing-review and editing. XL contributed to conceptualization, software and writing-review and editing. RH was involved in methodology and writing-review and editing. AP contributed to supervision, resources and writing-review and editing. VB was involved in methodology and writing-review and editing. RP contributed to methodology and writing-review and editing. $\mathrm{MH}$ was involved in supervision, resources and writing-review and editing. VP contributed to conceptualization, supervision, resources, funding acquisition, project administration and writing-review and editing.

\section{Funding}

This work was supported by the Russian Science Foundation under Grant No. 19-79-30002.

\section{Declarations}

Conflict of interest The authors report no declarations of interest.

Open Access This article is licensed under a Creative Commons Attribution 4.0 International License, which permits use, sharing, adaptation, distribution and reproduction in any medium or format, as long as you give appropriate credit to the original author(s) and the source, provide a link to the Creative Commons licence, and indicate if changes were made. The images or other third party material in this article are included in the article's Creative Commons licence, unless indicated otherwise in a credit line to the material. If material is not included in the article's Creative Commons licence and your intended use is not permitted by statutory regulation or exceeds the permitted use, you will need to obtain permission directly from the copyright holder. To view a copy of this licence, visit http://creativecommons.org/licen ses/by/4.0/.

\section{References}

[1] Otsuka K, Ren X (2005) Physical metallurgy of Ti-Ni-based shape memory alloys. Prog Mater Sci 50:511-678. https://d oi.org/10.1016/j.pmatsci.2004.10.001

[2] Kurita T, Matsumoto H, Abe H (2004) Phase transformation behavior of Ti-rich NiTi alloy by a calorimetric method. J Mater Sci 39:4391-4392. https://doi.org/10.1023/B:JMSC. $0000033435.24088 .2 \mathrm{c}$

[3] Wagner MFX, Dey SR, Gugel H, Frenzel J, Somsen C, Eggeler G (2010) Effect of low-temperature precipitation on the transformation characteristics of Ni-rich NiTi shape memory alloys during thermal cycling. Intermetallics 18:1172-1179. https://doi.org/10.1016/j.intermet.2010.02. 048

[4] Cui J, Chu YS, Famodu OO, Furuya Y, Hattrick-Simpers J, James RD, Ludwig A, Thienhaus S, Wuttig M, Zhang Z, Takeuchi I (2006) Combinatorial search of thermoelastic shape-memory alloys with extremely small hysteresis width. Nat Mater 5:286-290. https://doi.org/10.1038/nmat1593

[5] Epps JJ, Chopra I (2001) In-flight tracking of helicopter rotor blades using shape memory alloy actuators. Smart Mater Struct 10:104-111. https://doi.org/10.1088/0964-1726/10/1/ 310

[6] Saadat S, Salichs J, Noori M, Hou Z, Davoodi H, Bar-on I, Suzuki Y, Masuda A (2002) An overview of vibration and seismic applications of NiTi shape memory alloy. Smart Mater Struct 11:218-229. https://doi.org/10.1088/0964-172 $6 / 11 / 2 / 305$

[7] Jani JM, Leary M, Subic A, Gibson MA (2014) A review of shape memory alloy research applications and opportunities. Mater Des 56:1078-1113

[8] Shabalovskaya SA (1996) On the nature of the biocompatibility and on medical applications of NiTi shape memory and superelastic alloys Bio-med. Mater Eng 6:267-289. h ttps://doi.org/10.3233/BME-1996-6405

[9] Sattar T, Manzoor T, Khalid FA, Akmal M, Saeed G (2019) Improved in vitro bioactivity and electrochemical behavior 
of hydroxyapatite-coated NiTi shape memory alloy. J Mater Sci 54:7300-7306. https://doi.org/10.1007/s10853-018-033 04-8

[10] Elahinia MH, Hashemi M, Tabesh M, Bhaduri SB (2012) Manufacturing and processing of NiTi implants: a review. Prog Mater Sci 57(5):911-946

[11] Farber E, Zhu J-N, Popovich A, Popovich V (2020) A review of NiTi shape memory alloy as a smart material produced by additive manufacturing. Mater Today Proc 30:761-767. https://doi.org/10.1016/j.matpr.2020.01.563

[12] Zhu J-N, Borisov E, Liang X, Farber E, Hermans MJM, Popovich VA (2021) Predictive analytical modelling and experimental validation of processing maps in additive manufacturing of nitinol alloys. Addit Manuf 38:101802. h ttps://doi.org/10.1016/j.addma.2020.101802

[13] Dehghanghadikolaei A, Ibrahim H, Amerinatanzi A, Hashemi M, Moghaddam NS, Elahinia M (2019) Improving corrosion resistance of additively manufactured nickel-titanium biomedical devices by micro-arc oxidation process. J Mater Sci 54:7333-7355. https://doi.org/10.1007/s10853019-03375-1

[14] Gorgin Karaji Z, Speirs M, Dadbakhsh S, Kruth JP, Weinans HIED, Zadpoor AA, Amin Yavari SIED (2017) Additively manufactured and surface biofunctionalized porous nitinol. ACS Appl Mater Interfaces 9(2):1293-1304

[15] Speirs M, Van Hooreweder B, Van Humbeeck J, Kruth JP (2017) Fatigue behaviour of NiTi shape memory alloy scaffolds produced by SLM, a unit cell design comparison. J Mech Behav Biomed Mater 70:53-59. https://doi.org/10. 1016/j.jmbbm.2017.01.016

[16] Yang Y, Zhan JB, Sui JB, Li CQ, Yang K, Castany P, Gloriant T (2020) Functionally graded NiTi alloy with exceptional strain-hardening effect fabricated by SLM method. Scripta Mater 188:130-134. https://doi.org/10.1016/j.scripta mat.2020.07.019

[17] Wang X, Speirs M, Kustov S, Vrancken B, Li X, Kruth J-P, Van Humbeeck J (2018) Selective laser melting produced layer-structured NiTi shape memory alloys with high damping properties and Elinvar effect. Scripta Mater 146:246-250. https://doi.org/10.1016/j.scriptamat.2017.11. 047

[18] Saedi S, Shayesteh Moghaddam N, Amerinatanzi A, Elahinia M, Karaca HE (2018) On the effects of selective laser melting process parameters on microstructure and thermomechanical response of Ni-rich NiTi. Acta Mater 144:552-560

[19] Dadbakhsh S, Speirs M, Kruth J-P, Schrooten J, Luyten J, Van Humbeeck J (2014) Effect of SLM Parameters on transformation temperatures of shape memory nickel titanium parts. Adv Eng Mater 16:1140-1146. https://doi. org/10.1002/adem.201300558

[20] Bormann T, Schumacher R, Müller B, Mertmann M, de Wild M (2012) Tailoring selective laser melting process parameters for NiTi implants. J Mater Eng Perform 21:2519-2524. https://doi.org/10.1007/s11665-012-0318-9

[21] Haberland C, Elahinia M, Walker JM, Meier H, Frenzel J (2014) On the development of high quality NiTi shape memory and pseudoelastic parts by additive manufacturing. Smart Mater Struct 23:104002. https://doi.org/10.1088/096 4-1726/23/10/104002

[22] Xue L, Atli KC, Picak S, Zhang C, Zhang B, Elwany A, Arroyave R, Karaman I (2021) Controlling martensitic transformation characteristics in defect-free NiTi shape memory alloys fabricated using laser powder bed fusion and a process optimization framework. Acta Mater 215:117017. https://doi.org/10.1016/j.actamat.2021.117017

[23] Nguyen QB, Luu DN, Nai SML, Zhu Z, Chen Z, Wei J (2018) The role of powder layer thickness on the quality of SLM printed parts. Arch Civ Mech Eng 18:948-955. http s://doi.org/10.1016/j.acme.2018.01.015

[24] Ahn IH (2019) Determination of a process window with consideration of effective layer thickness in SLM process. Int J Adv Manuf Technol 105:4181-4191. https://doi.org/10. 1007/s00170-019-04402-w

[25] Herzog D, Seyda V, Wycisk E, Emmelmann C (2016) Additive manufacturing of metals. Acta Mater 117:371-392

[26] Khorasani AM, Gibson I, Ghasemi A, Ghaderi A (2019) A comprehensive study on variability of relative density in selective laser melting of Ti-6Al-4V. Virtual Phys Prototyp 14:349-359

[27] Greco S, Gutzeit K, Hotz H, Kirsch B, Aurich JC (2020) Selective laser melting (SLM) of AISI 316L-impact of laser power, layer thickness, and hatch spacing on roughness, density, and microhardness at constant input energy density. Int J Adv Manuf Technol 108:1551-1562

[28] Xia M, Gu D, Yu G, Dai D, Chen H, Shi Q (2016) Influence of hatch spacing on heat and mass transfer, thermodynamics and laser processability during additive manufacturing of Inconel 718 alloy. Int J Mach Tools Manuf 109:147-157

[29] Ma J, Franco B, Tapia G, Karayagiz K, Johnson L, Liu J, Arroyave R, Karaman I, Elwany A (2017) Spatial control of functional response in 4D-printed active metallic structures. Sci Rep 7:46707

[30] Cao Y, Zhou X, Cong D, Zheng H, Cao Y, Nie Z, Chen Z, Li S, Xu N, Gao Z, Cai W, Wang Y (2020) Large tunable elastocaloric effect in additively manufactured $\mathrm{Ni}-\mathrm{Ti}$ shape memory alloys. Acta Mater 194:178-189

[31] McCue ID, Valentino GM, Trigg DB, Lennon AM, Hebert CE, Seker DP, Nimer SM, Mastandrea JP, Trexler MM, 
Storck SM (2021) Controlled shape-morphing metallic components for deployable structures. Mater Des 208:109935

[32] Frenzel J, George EP, Dlouhy A, Somsen C, Wagner MFX, Eggeler G (2010) Influence of $\mathrm{Ni}$ on martensitic phase transformations in NiTi shape memory alloys. Acta Mater 58:3444-3458

[33] Allafi JK, Dlouhy A, Neuking K, Eggeler G (2001) Influence of precipitation and dislocation substructure on phase transformation temperatures in a Ni-rich NiTi-shape memory alloy. J Phys IV 11:529-534

[34] Eggeler GF, Neuking K, Dlouhy A, Kobus E (2000) Creep behavior of NiTi shape memory alloys and the effect of precreep on the martensitic phase transformation. Mater Sci Forum 327:183-186

[35] Waitz T, Antretter T, Fischer FD, Simha NK, Karnthaler HP (2007) Size effects on the martensitic phase transformation of NiTi nanograins. J Mech Phys Solids 55:419-444

[36] Gil FJ, Manero JM, Planell JA (1995) Effect of grain size on the martensitic transformation in NiTi alloy. J Mater Sci 30:2526-2530

[37] Tang W, Sundman B, Sandström R, Qiu C (1999) New modelling of the $\mathrm{B} 2$ phase and its associated martensitic transformation in the $\mathrm{Ti}-\mathrm{Ni}$ system. Acta Mater 47:3457-3468

[38] Zhu J, Wu H-H, Wu Y, Wang H, Zhang T, Xiao H, Wang Y, Shi S-Q (2021) Influence of Ni4Ti3 precipitation on martensitic transformations in NiTi shape memory alloy: R phase transformation. Acta Mater 207:116665

[39] Braun J, Kaserer L, Stajkovic J, Leitz KH, Tabernig B, Singer P, Leibenguth P, Gspan C, Kestler H, Leichtfried G (2019) Molybdenum and tungsten manufactured by selective laser melting: analysis of defect structure and solidification mechanisms. Int J Refract Met Hard Mater 84:104999

[40] Bormann T, Müller B, Schinhammer M, Kessler A, Thalmann P, de Wild M (2014) Microstructure of selective laser melted nickel-titanium. Mater Charact 94:189-202

[41] Raghavan S, Zhang B, Wang P, Sun C-N, Nai MLS, Li T, Wei J (2017) Effect of different heat treatments on the microstructure and mechanical properties in selective laser melted INCONEL 718 alloy. Mater Manuf Processes 32:1588-1595

[42] Luo S, Gao P, Yu H, Yang J, Wang Z, Zeng X (2019) Selective laser melting of an equiatomic $\mathrm{AlCrCuFeNi}$ highentropy alloy: processability, non-equilibrium microstructure and mechanical behavior. J Alloys Compd 771:387-397

[43] Mahmoudi M, Tapia G, Franco B, Ma J, Arroyave R, Karaman I, Elwany A (2018) On the printability and transformation behavior of nickel-titanium shape memory alloys fabricated using laser powder-bed fusion additive manufacturing. J Manuf Process 35:672-680

[44] Tadayyon G, Mazinani M, Guo Y, Zebarjad SM, Tofail SA, Biggs MJ (2016) The effect of annealing on the mechanical properties and microstructural evolution of Ti-rich NiTi shape memory alloy. Mater Sci Eng: A 662:564-577

[45] Rai AK, Trpathy H, Hajra RN, Raju S, Saroja S (2017) Thermophysical properties of Ni based super alloy 617 . J Alloys Compd 698:442-450

[46] Zanotti C, Giuliani P, Riva G, Tuissi A, Chrysanthou A (2009) Thermal diffusivity of Ni-Ti SMAs. J Alloys Compd 473:231-237

[47] Lampa C, Kaplan AFH, Powell J, Magnusson C (1997) An analytical thermodynamic model of laser welding. J Phys D: Appl Phys 30:1293-1299

[48] Li Y, Zhou K, Tan P, Tor SB, Chua CK, Leong KF (2018) Modeling temperature and residual stress fields in selective laser melting. Int J Mech Sci 136:24-35

[49] Tang M, Pistorius PC, Beuth JL (2017) Prediction of lack-offusion porosity for powder bed fusion. Addit Manuf $14: 39-48$

[50] Fischer P, Romano V, Weber HP, Karapatis NP, Boillat E, Glardon R (2003) Sintering of commercially pure titanium powder with a Nd:YAG laser source. Acta Mater 51:1651-1662

[51] Yeom J-T, Kim JH, Hong J-K, Kim SW, Park C-H, Nam TH, Lee K-Y (2014) Hot forging design of as-cast NiTi shape memory alloy. Mater Res Bull 58:234-238

[52] Mentz J, Bram M, Buchkremer HP, Stöver D (2006) Improvement of Mechanical properties of powder metallurgical niti shape memory alloys. Adv Eng Mater 8:247-252

[53] Parvizi S, Hashemi SM, Asgarinia F, Nematollahi M, Elahinia M (2021) Effective parameters on the final properties of NiTi-based alloys manufactured by powder metallurgy methods: a review. Prog Mater Sci 117:100739

[54] Yan F, Xiong W, Faierson EJ (2017) Grain structure control of additively manufactured metallic materials. Materials 10:1260

[55] Khelfaoui F, Guénin G (2003) Influence of the recovery and recrystallization processes on the martensitic transformation of cold worked equiatomic Ti-Ni alloy. Mater Sci Eng A 355:292-298

[56] Maass B, Burow J, Frenzel J, Eggeler G (2009) On the influence of crystal defects on the functional stability of NiTi based shape memory alloys. In European Symposium on Martensitic Transformations

[57] Nishida M, Wayman CM, Honma T (1986) Precipitation processes in near-equiatomic TiNi shape memory alloys. Metall Trans A 17:1505-1515. https://doi.org/10.1007/ BF02650086 
[58] Bigelow GS, Padula SA, Garg A, Gaydosh D, Noebe RD (2010) Characterization of ternary nitipd high-temperature shape-memory alloys under load-biased thermal cycling. Metall Mater Trans A Phys Metall Mater Sci 41:3065-3079

[59] Gu D, Ma C, Dai D, Yang J, Lin K, Zhang H, Zhang H (2021) Additively manufacturing-enabled hierarchical NiTibased shape memory alloys with high strength and toughness. Virtual Phys Prototyp 16:S19-S38

[60] Chen G, Liu J, Dong Z, Li Y, Zhao Y, Zhang B, Cao J (2021) Understanding mechanisms of shape memory function deterioration for nitinol alloy during non-equilibrium solidification by electron beam. J Adv Res 33:99-108

[61] Hu L, Jiang S, Liu S, Zhang Y, Zhao Y, Zhao C (2016) Transformation twinning and deformation twinning of NiTi shape memory alloy. Mater Sci Eng: A 660:1-10

[62] Zhou YH, Li WP, Wang DW, Zhang L, Ohara K, Shen J, Ebel T, Yan M (2019) Selective laser melting enabled additive manufacturing of $\mathrm{Ti}-22 \mathrm{Al}-25 \mathrm{Nb}$ intermetallic: excellent combination of strength and ductility, and unique microstructural features associated. Acta Mater 173:117-129

[63] Zhang Q, Hao S, Liu Y, Xiong Z, Guo W, Yang Y, Ren Y, Cui L, Ren L, Zhang Z (2020) The microstructure of a selective laser melting (SLM)-fabricated NiTi shape memory alloy with superior tensile property and shape memory recoverability. Appl Mater Today 19:100547

[64] Fu J, Brouwer JC, Hendrikx RWA, Richardson IM, Hermans MJM (2020) Microstructure characterisation and mechanical properties of ODS Eurofer steel subject to designed heat treatments. Mater Sci Eng: A 770:138568

[65] Ungár T, Gubicza J, Hanák P, Alexandrov I (2001) Densities and character of dislocations and size-distribution of subgrains in deformed metals by X-ray diffraction profile analysis. Mater Sci Eng: A 319:274-278

[66] Maniammal K, Madhu G, Biju V (2017) X-ray diffraction line profile analysis of nanostructured nickel oxide: shape factor and convolution of crystallite size and microstrain contributions. Physica E 85:214-222

[67] Mote VD, Purushotham Y, Dole BN (2012) Williamson-Hall analysis in estimation of lattice strain in nanometer-sized ZnO particles. J Theor Appl Phys 6(1):6

[68] Kim Y-Y, Schenk AS, Ihli J, Kulak AN, Hetherington NBJ, Tang CC, Schmahl WW, Griesshaber E, Hyett G, Meldrum FC (2014) A critical analysis of calcium carbonate mesocrystals. Nat Commun 5:4341

[69] Williamson GK, Hall WH (1953) X-ray line broadening from filed aluminium and wolfram. Acta Metall 1:22-31

[70] Biju V, Sugathan N, Vrinda V, Salini SL (2008) Estimation of lattice strain in nanocrystalline silver from X-ray diffraction line broadening. J Mater Sci 43:1175-1179
[71] Bokuchava G (2016) Materials microstructure characterization using high resolution time-of-flight neutron diffraction. Rom J Phys 61:903-925

[72] Lin Y-S, Cak M, Paidar V, Vitek V (2012) Why is the slip direction different in different B2 alloys? Acta Mater 60:881-888

[73] Cayron C (2020) What EBSD and TKD Tell Us about the crystallography of the martensitic B2-B19' transformation in NiTi shape memory alloys. Crystals 10(7):562

[74] Yin YJ, Sun JQ, Guo J, Kan XF, Yang DC (2019) Mechanism of high yield strength and yield ratio of $316 \mathrm{~L}$ stainless steel by additive manufacturing. Mater Sci Eng: A 744:773-777

[75] Waitz T, Kazykhanov V, Karnthaler HP (2004) Martensitic phase transformations in nanocrystalline NiTi studied by TEM. Acta Mater 52:137-147

[76] Natter H, Löffler MS, Krill CE, Hempelmann R (2001) Crystallite growth of nanocrystalline transition metals studied in situ by high temperature synchrotron X-ray diffraction. Scripta Mater 44:2321-2325

[77] Kockar B, Karaman I, Kim JI, Chumlyakov YI, Sharp J, Yu CJ (2008) Thermomechanical cyclic response of an ultrafinegrained NiTi shape memory alloy. Acta Mater 56:3630-3646

[78] Golberg D, Xu Y, Murakami Y, Otsuka K, Ueki T, Horikawa H (1995) High-temperature shape memory effect in Ti50Pd50 - xNix $(\mathrm{x}=10,15,20)$ alloys. Mater Lett 22:241-248

[79] Golberg D, Xu Y, Murakami Y, Morito S, Otsuka K, Ueki T, Horikawa H (1995) Characteristics of Ti50Pd30Ni20 hightemperature shape memory alloy. Intermetallics 3:35-46

[80] Kockar B, Karaman I, Kim JI, Chumlyakov Y (2006) A method to enhance cyclic reversibility of NiTiHf high temperature shape memory alloys. Scripta Mater 54:2203-2208

[81] Attaran M (2017) The rise of 3-D printing: the advantages of additive manufacturing over traditional manufacturing. Bus Horiz 60:677-688

[82] Matsumoto H (2003) Transformation behaviour with thermal cycling in NiTi alloys. J Alloys Compd 350:213-217

[83] Burow J, Prokofiev E, Somsen C, Frenzel J, Valiev R, Eggeler GF (2008) Martensitic transformations and functional stability in ultra-fine grained NiTi shape memory alloys. Mater Sci Forum 584-586:852-857. https://doi.org/ 10.4028/www.scientific.net/MSF.584-586.852

[84] Morgan NB, Friend CM (2001) A review of shape memory stability in NiTi alloys. J Phys Iv 11:325-332

[85] Yan F, Xiong W, Faierson EJ (2017) Grain structure control of additively manufactured metallic materials. Materials 10(11): 1260

[86] Kou S (2003) Welding metallurgy. New Jersey USA 431(446):223-225 
[87] Thijs L, Sistiaga MLM, Wauthle R, Xie Q, Kruth JP, Van Humbeeck J (2013) Strong morphological and crystallographic texture and resulting yield strength anisotropy in selective laser melted tantalum. Acta Mater 61(12):4657-4668

[88] Seede R, Shoukr D, Zhang B, Whitt A, Gibbons S, Flater P, Elwany A, Arroyave R, Karaman I (2020) An ultra-high strength martensitic steel fabricated using selective laser melting additive manufacturing: densification, microstructure, and mechanical properties. Acta Mater 186:199-214

Publisher's Note Springer Nature remains neutral with regard to jurisdictional claims in published maps and institutional affiliations. 